Muralidharan,S., Krishnankutty,P., Hwang, B.G., Caldas,C., and Mulva, S. (2018). "Enhancing labour productivity in petrochemical construction and maintenance projects." In: Proc. $26^{\text {th }}$ Annual Conference of the International. Group for Lean Construction (IGLC), González, V.A. (ed.), Chennai, India, pp. 829-839. DOI: doi.org/10.24928/2018/0526. Available at: www.iglc.net.

\title{
ENHANCING LABOUR PRODUCTIVITY IN PETROCHEMICAL CONSTRUCTION AND MAINTENANCE PROJECTS
}

\author{
Sriya Muralidharan', Pramesh Krishnankutty ${ }^{2}$, \\ Bon-Gang Hwang ${ }^{3}$, Carlos Caldas ${ }^{4}$, Stephen Mulva ${ }^{5}$
}

\begin{abstract}
Construction labour is a significant cost factor for petrochemical plant owners and their contractors. Enhancing labour productivity is therefore indispensable for the petrochemical industry in order to achieve sustainable development. Considering the variety of projects undertaken by this industry (i.e. construction and more particularly, maintenance and shutdowns/turnarounds), there is a lack of standard methods for assessing labour productivity. This generates a need for developing productivity assessment practices suitable for all project types. This paper presents solutions for labour productivity improvement based on a study conducted at various petrochemical plants. The study developed and implemented a modified Activity Analysis method suitable for the site conditions, with a focus on maintenance activities and shutdown/turnaround projects, which were rarely considered on previous productivity assessment approaches. Conducted over two cycles, this study assessed the current labour productivity, identified barriers, and analysed the efficacy of solutions implemented to mitigate these barriers. The aggregate direct work percentage was found to have increased in the second cycle. The analysis of labour productivity through Activity Analysis in maintenance and shutdown/turnaround projects is a key contribution of this study. The findings provide a basis for assessing and benchmarking labour productivity in the petrochemical industry.
\end{abstract}

\section{KEYWORDS}

Labour, Productivity, Activity Analysis, Continuous improvement, Benchmarking

1 Research Assistant, Department of Building, National University of Singapore, 4 Architecture Drive, Singapore, 117566, +65 8696 8214, bdgsriy@ nus.edu.sg

2 Research Associate, Department of Building, National University of Singapore, 4 Architecture Drive, Singapore, 117566, +65 90998262, bdgkp@ nus.edu.sg

3 Associate Professor, Department of Building, National University of Singapore, 4 Architecture Drive, Singapore, 117566, +65 8138 4674, bdghbg@ nus.edu.sg

4 Professor, Department of Civil, Architectural and Environmental Engineering, University of Texas at Austin, TX, USA, +1 (512) 471-6014, caldas@ mail.utexas.edu

5 Director, Construction Industry Institute, Austin, TX, USA, +1 (512) 232-3013, smulva@cii.utexas.edu 
Sriya Muralidharan, Pramesh Krishnankutty, Bon-Gang Hwang,

Carlos Caldas, Stephen Mulva

\section{INTRODUCTION}

Low cost of labour has been a key driver of economic growth in several nations(Auyong 2014). Yet, growing concerns over societal issues like ageing(Fish 2015)and tightening immigration(Auyong 2014)have forced governments to reorient towards productivitydriven economic growth. For instance, Singapore has set a bold target of $2 \%$ to $3 \%$ annual productivity growth for the decade leading up to 2020 (ESC 2010). To achieve this, it is essential to focus on the energy and chemicals industry, which accounts for nearly $34 \%$ of the total manufacturing output. Singapore's Jurong Island hosts several major energy and chemical companies and has attracted investments exceeding 35 billion Singapore Dollars (S\$) (EDB 2014). Moreover, the labour cost in the manufacturing sector accounted for the largest share of total business costs. Unit labour cost (manufacturing and service sector) increased by $2.8 \%$ for 2015 due to a slight decrease in productivity and increased remuneration(MTI 2015).In view of this and tightening foreign labour policy(Ministry of Manpower (MOM) 2017), the Process Construction and Maintenance Management Committee (PCMMC) was formed in 2013, by Singapore government agencies along with plant owners, contractors, the Singapore Chemical Industry Council, and Association of Process Industry (ASPRI) to improve craft worker and project productivity(ASPRI 2015).

\section{BACKGROUND}

\section{PRODUCTIVITY MEASUREMENT AND IMPROVEMENT}

There has been an increasing focus on the application of lean principles to construction since the 1990s(Ballard and Howell 1994). Lean construction categorises production activities as either a value-adding or non-value adding activity (of no value to the consumer) (Koskela 2000). Specifically, the reduction of non-value adding activities (waste) has been identified by Koskela (1992) as a fundamental driver for enhanced productivity. However, to attain enhanced productivity, an understanding of current labour productivity is necessary. Yet, there is no unanimous definition for productivity that fits all situations and suitable productivity measurements(Yi and Chan 2014). Various researchers agreethat productivity is a ratio of output and input(Bernolak 1997; CII 2010). Productivity can be measured in two ways based on measurement aims and data availability namely: (1) total factor productivity (TFP), which examines outputs and all inputs; and (2) partial factor productivity (PFP), in which outputs and one or few chosen inputs are studied(Rakhra 1991). Labour productivity becomes a crucial PFP index due to the concentration manpower required to accomplish a task (Yi and Chan 2014). Continuous productivity measurement and comparison of data from different projects has been highlighted as key to improving construction productivity (Liou and Borcherding 1986). There fore, there is a critical need for a common productivity measurement method fit for all projects, companies and countries(Ingvaldsen et al. 2004). Singapore uses the value-added per employed person as the labour productivity index (SPRING Singapore 2011). This has limitations in international comparison and is inconsistent due to varying factors. Hence, there is a definite need for research in 
measuring on-site labour productivity in construction, maintenance and shutdown/turnaround projects in the energy and chemical sector. Furthermore, benchmarking is seldom used by contractor firms in Singapore (Hwang et al. 2013f). The Productivity Council of Singapore has hence collaborated with the Construction Industry Institute (CII), the University of Texas at Austin (UT), and National University of Singapore (NUS) to introduce best practices, metrics, and benchmarking for the Process, Construction and Maintenance (PCM) industry. As a first step, this research aimed to (1) assess labour efficiency in Singapore's petrochemical projects in terms of craft worker time distribution; (2) investigate reasons for non-value-added work hours; and (3) recommend best practices and guidelines to reduce non-productive activities and delays, and therefore improve labour productivity. The Activity Analysis method was chosen as it enables plant owners and contractors, to jointly measure project-level productivity and benchmark craft workers' efficiency in terms of worker time distribution(ASPRI 2015).

\section{ACTIVITY ANALYSIS - THEORETICAL BACKGROUND}

Productivity can be measured either be at the macro-level or micro-level. Macro-level productivity concerns contracting arrangements, labour laws, and organization; while micro-level productivity is measured based on-site management, execution, and operation, mainly at the job site (Dozzi and AbouRizk 1993).Activity Analysis is an indirect measurement method of labour performance at the micro-level. It is a continuous productivity improvement process that measures the time expended by workers on-site and determines hurdles to productivity which should be mitigated or eliminated to improve the direct-work rates (CII 2010; Gouett et al. 2011). It is an advanced form of the work sampling method. Work or occurrence sampling is an easy and inexpensive method used to measure the time individuals spend in various categories of activities(Josephson and Björkman 2013). In this method, an unbiased observer shadows one or more individuals and records their activities at specific times. Activity samples observed by this method at random from a big group of craftwork activities on a project tend to reflect the distribution pattern as the group itself(AACE International 2004). Work sampling has been used since the 1930s for monitoring knitting mills(Tippett 1935). Work sampling was then defined as the observation of labourers at fixed or random, infrequent intervals through the day (Buchholz et al. 1996)which provides the estimated time spent by a craft labour on various activities. Snap-reading, an important technique in the work-sampling method, refers to capturing the exact moment when the sample is taken without any information on the events prior to or after the moment (Gouett et al. 2011). When numerous samples are collecting using this technique, the sample mean was found to tend to the mean of the unknown population (Tippett 1935). Five-minute rating and occurrence sampling were used to measure labour utilization(Gong et al. 2011) and the average direct work percentage was found to be around $45.9 \%$. Work sampling is also used to benchmark direct-work rates in few large construction companies(Gouett et al. 2011). However, work sampling method has drawbacks such as difficulties to implement, identify root causes and provide recommendations for improvement. Activity Analysis, however, includes observation and categorization of labour activities at a plant or construction site, planning and implementing improvement strategies, thereby improving 
Sriya Muralidharan, Pramesh Krishnankutty, Bon-Gang Hwang,

Carlos Caldas, Stephen Mulva

productivity. Activity Analysis shares similar objectives with Value Stream Mapping (VSM), a powerful tool for lean implementation. VSM aims to reduce waste from production activities (value-streams) by mapping their current state to a future-state (ideal, waste-free) (Arbulu and Tommelein 2002). The gap between these states provides a roadmap for improvement. Hence, Activity Analysis may be construed as a VSM tool that facilitates the implementation of lean construction. It provides quick and actionable feedback to the management onworkers' performance. Activity Analysis not only diagnoses workforce issues but also identifies root causes and recommends best practices for continuous improvement.(CII 2010)

\section{Activity Categories and Sample Size}

Koskela (1992)emphasized that identification and elimination of non-value adding activities could facilitate enhanced construction productivity. Several non-value adding activities including poor planning, delays, travel, lack of tools, materials and job instructions have been identified by lean scholars (Ballard and Howell 1998; Josephson and Björkman 2013; Koskela 2000). Hence, extensive background research with NUS, The University of Texas (UT) at Austin, CII, and Singapore petrochemical industry representatives was performed to determine the appropriate categories for labour-time utilisation. Activity categories and subcategories were modified to suit Singapore site conditions. Worker time was classified into direct work and non-direct work. The nondirect work consisted of supportive work (semi-productive work), such as preparatory work, material handling, and idle (non-productive work) such as waiting for material and tools(Gong et al. 2011). Existing activity categories (CII 2010; Dozzi and AbouRizk 1993; Gouett et al. 2011) were analysed and the following categories were adopted:

- Direct work: Exerting physical effort in carrying out an activity or assisting an activity. Involves installation of materials and/or equipment by workers as well as the physical effort of support groups. This could be observed either during installation or demolition. For e.g., installing forms, pipes, casting concrete

- Waiting for Permits: Periods of waiting for authorisation to proceed, even if workers are attentive to ongoing work by other craft workers. For instance, waiting for permits, or for task completion sign-off, or to obtain entry to the work area.

- Waiting for Instruction: Waiting for instruction from foreman or for a job allotment

- Waiting for Material: Examples include waiting in line at a storage warehouse, material/parts storage area, or waiting for the return of a concrete bucket.

- Waiting for Equipment: For instance, waiting for a crane to hook to return for the next lift or waiting for another craft worker to finish utilizing tools or equipment.

- Waiting for Quality Assurance/Quality Control $(Q A / Q C)$ :Labour waiting for the QA/QC assessment to be completed

- Waiting for Unknown: Crew waiting at the workplacefor unknown reasons 
- Preparatory work: Supporting works such as obtaining assignments and defining requirements prior to commencing tasks including stretching activities, safety/toolbox talks, start-card processes and planning of the work at the workface.

- Material handling: Actions directed towards obtaining, adjusting and transporting material inside the plant, excluding transport of beams, pipe spools, permanent plant equipment, rebar etc. into final position or in the general task area.

- Tools and Equipment: Activities related to obtaining, transporting, adjusting tools or equipment to facilitate performance of direct work activities

- Travel: Workers walking or riding sans tools, materials or technical information.

- Personal: Idleness or time-taken away from work during normal work-hours excluding normally scheduled breaks and lunch periods.

Activity Analysis follows a multinomial distribution rather than a binomial distribution, as several activity categories are considered (CII 2010). The sample size for simultaneously estimating population parameters within a distance of the true values at different significant levels can be determined (Thompson 1987). In the proposed method, for a confidence level of $95 \%$, the sample size is 510 . However, if the worker population is below 510, the minimum observation required can be calculated by the number of craft workers $(\mathrm{N})$ and minimum observations $\left(n_{o}\right)$ in Eq. (1). The observations per hour may be staggered over few days thereby mitigating the limitations in achieving the required sample size in a single hour. For instance, for 150 workers, the sample size would be 116per hour as per Eq.(1). The116 samples may be collected over many days in the same one hour duration as the purpose is to observe workers' behaviour at a specified time.

$$
n=\frac{1}{\frac{1}{n_{0}}+\frac{1}{N}}
$$

\section{RESEARCH METHOD AND DATA PRESENTATION}

Activity Analysis was conducted in a five-step process including plan study, sample, analyse, plan and implement improvements (Caldas et al. 2016; CII 2010; Gouett et al. 2011) and was modified substantially toreflect the site conditions and maintenance activities, shutdowns, and turnarounds. A second round of Activity Analysis was conducted to verify continuous productivity improvement.

Plan Study: This step included developing the goals of the study, defining the activity categories and minimum sample size, training the researchers, obtaining craft information, and determining sampling routes and times (Gouett et al. 2011). Training sessions on the Activity Analysis method, data-collection device usage and site-training were conducted to enhance the knowledge of the data collection team. The session enabled companies to select appropriate projects. A pre-information sheet requesting project details, contractors involved, and the scope of work was circulated to the plant owners for understanding the site conditions. The first cycle of 10 pilot projects were selected from five facility owners. 
Sriya Muralidharan, Pramesh Krishnankutty, Bon-Gang Hwang,

Carlos Caldas, Stephen Mulva

Sample: The researchers accompanied by the owner company stafftread randomlyselected predefined routes for observation, focusing purely on the sampling of craft workers. The snap-reading technique was employed to observe the worker and categorize the activity accurately. The information including company, work type (e.g.: equipment, concrete, piping), and number of workers observed at that time under each activity category (e.g. installation, waiting for a permit, material handling) was recorded on an Activity Analysis software. The software, custom-made by CII for this study, could automatically provide timestamps, the cumulative number of observations in each category and save all the information. The company staff also provided key site-specific inputs which benefitted researchers in identifying causes for non-direct work hours and planning improvements.

Analyse: Data analysis was targeted at quantifying the productive (direct work) and non-productive work times. An automatic report generation tool was also developed on the Microsoft Excel platform. Workers' time distribution was analysed with respect to (1) work categories, like direct work, waiting, and preparatory work; (2) work types, such as concrete, painting and instrumentation; (3) time of the day; and (4) contractor.

Plan for Improvements: Each participant company was provided with a report of the analysis results, observations, barriers to productivity and areas for planning and implementing improvements. Several post-survey meetings with each plant owner were held to discuss the results and their interpretation to the top management and contractors. The plant owner decided on the adoption of the improvement strategies based on feasibility, logistics, available human resources, implementation cost and schedule.

Implement Improvements: The selected improvement strategies were implemented and their effect on productivity improvement was measured by conducting another round of Activity Analysis. Prior to the second round, individual meetings were held with each participant plant owner to discuss the adopted solutions and the implementation progress.

Activity data were collected at five different Singapore petrochemical plants. Two cycles of data collection in 18 projects were conducted to measure existing labour efficiency and the improvement after implementing solutions. Samples from each project were collected over two to three days depending on the average number of craft working, logistics and schedule, and the weather. In the first cycle, activity data was collected from ten pilot projects covering the three project types(i.e. 3 maintenance, 3construction, and 4 shutdown/turnaround projects). Due to time and site constraints, only eight of the ten pilot projects (i.e. 3 maintenance, 2 construction, and 2 shutdown/turnaround projects) were selected for the second cycle data collection. Upon analysis, the data of one project in the second cycle was found unsuitable for comparison due to large work scope variation between cycles. Thus, seven projects from the second cycle were analysed.

\section{RESULTS AND DISCUSSION}

Aggregate Direct Work Percentage in the first cycle is presented in Table 1. The overall aggregate direct work percentage was $29.5 \%$. However, the $70.5 \%$ non-direct work time consisted of supporting activities such as preparatory work, material handling, and tools and equipment. The craft workers were noted to spend significant time on travel $(23.8 \%)$, 
material handling (15.7\%), preparatory work (13.0\%), and waiting for instruction $(7.0 \%)$. The overall direct work time was governed by "Equipment" trade (accounting for $34.36 \%$ ), characteristic of the process industry. Direct Work Percentage varied across project types due to the difference in work scopes. The aggregate direct work percentage for construction was $33.73 \%$ and $27.00 \%$ for the maintenance and shutdown/turnaround projects. The results for maintenance and shutdown/turnaround projects have been integrated for confidentiality. Rationally, higher aggregate direct work percentage for construction projects was expected. In comparison with other studies, direct work percentage in Singapore (33.73\%) was lower than in Alberta, Canada (50.7\%) (Hewage and Ruwanpura 2006) and industrial construction projects in the USA (50.4\%) (Gong et al. 2011). Evidently, the Singapore methodology categorised most of the direct work categories from the original method as preparatory work and material handling. Hence, cautious comparison must be made between the results. Table 2 reflects the variation of activity throughout the day. As expected, direct work percentage fluctuated over a typical work day and peaked during periods away from the day start (36.9\% from 10 am to 11 am), lunch break and towards day end (42.1\% from $2 \mathrm{pm}$ to $3 \mathrm{pm})$. In some shutdown/turnaround projects, the direct work percentage reached $41.0 \%$ at the day-end as data collection ended at 5 PM while the work shift was 24 hours. Craft workers spent significant time waiting (45.0\%) for permits, instruction and travelling (29.4\%) during the first hour of a workday and around lunch break (47.2\% \& 37.3\%). Significant material handling was prevalent all day.

Table 1: Summary of aggregate results for all pilot projects in the first cycle

\begin{tabular}{|c|c|c|c|c|c|}
\hline \multicolumn{2}{|c|}{ Work Type } & Work Category & Within Category & Across Category & Overall \\
\hline \multirow{13}{*}{ All } & Direct & Installation & $95.9 \%$ & $28.3 \%$ & \multirow{2}{*}{$29.5 \%$} \\
\hline & Work & Demolition & $4.1 \%$ & $1.2 \%$ & \\
\hline & \multirow{6}{*}{ Waiting } & Permits & $15.0 \%$ & $1.8 \%$ & \multirow{6}{*}{$12.0 \%$} \\
\hline & & Instruction & $58.3 \%$ & $7.0 \%$ & \\
\hline & & Material & $14.2 \%$ & $1.7 \%$ & \\
\hline & & Equipment & $3.0 \%$ & $0.4 \%$ & \\
\hline & & QA/QC & $3.3 \%$ & $0.4 \%$ & \\
\hline & & Unknown & $6.2 \%$ & $0.7 \%$ & \\
\hline & \multirow{5}{*}{ Other } & Preparatory Work & $22.2 \%$ & $13.0 \%$ & $13.0 \%$ \\
\hline & & Material Handling & $26.9 \%$ & $15.7 \%$ & $15.7 \%$ \\
\hline & & Tools and Equipment & $1.3 \%$ & $0.7 \%$ & $0.7 \%$ \\
\hline & & Travel & $40.7 \%$ & $23.8 \%$ & $23.8 \%$ \\
\hline & & Personal & $9.0 \%$ & $5.2 \%$ & $5.2 \%$ \\
\hline
\end{tabular}

Table 2: Summary of worker time distribution by work hours in the first cycle

\begin{tabular}{|c|c|c|c|c|c|c|c|c|}
\hline $\begin{array}{l}\text { Hour } \\
\text { Work Type }\end{array}$ & $\begin{array}{l}\text { 8:00 } \\
9: 00\end{array}$ & $\begin{array}{c}9: 00 \\
10: 00\end{array}$ & $\begin{array}{l}10: 00 \\
11: 00 \\
\end{array}$ & $\begin{array}{l}11: 00 \\
12: 00 \\
\end{array}$ & $\begin{array}{l}13: 00 \\
14: 00 \\
\end{array}$ & $\begin{array}{l}14: 00 \\
15: 00 \\
\end{array}$ & $\begin{array}{l}15: 00 \\
16: 00\end{array}$ & $\begin{array}{l}16: 00 \\
17: 00\end{array}$ \\
\hline Direct Work & $5.2 \%$ & $31.2 \%$ & $36.9 \%$ & $21.9 \%=$ & $23.9 \%$ & $42.1 \%$ & $36.4 \%$ & $41.0 \%$ \\
\hline
\end{tabular}


Sriya Muralidharan, Pramesh Krishnankutty, Bon-Gang Hwang,

Carlos Caldas, Stephen Mulva

\begin{tabular}{ccccccccc}
$\begin{array}{c}\text { Preparatory } \\
\text { Material }\end{array}$ & $8.5 \%$ & $15.4 \%$ & $\mathbf{1 7 . 4 \%}$ & $\mathbf{8 . 2 \%}$ & $13.1 \%$ & $14.5 \%$ & $13.1 \%$ & $14.7 \%$ \\
$\begin{array}{c}\text { Handling } \\
\text { Tools and }\end{array}$ & $10.6 \%$ & $\mathbf{1 8 . 2} \%$ & $\mathbf{1 9 . 1} \%$ & $10.9 \%$ & $14.6 \%$ & $\mathbf{1 7 . 3} \%$ & $\mathbf{1 7 . 8 \%}$ & $\mathbf{1 9 . 4 \%}$ \\
$\begin{array}{c}\text { Equipment } \\
\text { Waiting }\end{array}$ & $1.2 \%$ & $0.8 \%$ & $0.9 \%$ & $1.0 \%$ & $0.5 \%$ & $0.5 \%$ & $0.6 \%$ & $0.4 \%$ \\
$\quad \mathbf{4 5 . 0 \%}$ & $17.2 \%$ & $8.2 \%$ & $5.2 \%$ & $9.2 \%$ & $7.2 \%$ & $5.5 \%$ & $4.2 \%$ \\
Travel & $\mathbf{2 9 . 4 \%}$ & $14.2 \%$ & $9.5 \%$ & $\mathbf{4 7 . 2 \%}$ & $\mathbf{3 7 . 3} \%$ & $11.9 \%$ & $14.0 \%$ & $16.4 \%$ \\
Personal & $0.1 \%$ & $3.0 \%$ & $7.9 \%$ & $5.6 \%$ & $1.5 \%$ & $6.3 \%$ & $12.6 \%$ & $3.9 \%$ \\
\hline Total & $100 \%$ & $100 \%$ & $100 \%$ & $100 \%$ & $100 \%$ & $100 \%$ & $100 \%$ & $100 \%$ \\
\hline
\end{tabular}

\section{BEST PRACTICES AND IMPROVEMENT STRATEGIES}

This study further identified the following key areas with scope for improvement. Permitting: High waiting time for permits observed at the day-start could be reduced by issuing permits fifteen minutes before the scheduled start time and before the end of each toolbox meeting every day. Moreover, tools and material mobilization and preparatory works were recommended to start within fifteen minutes from the scheduled start time which would reduce the wait for instruction or materials. Lunch Break and Work Stoppage due to Bad Weather: Contractors were instructed on the time to travel for lunch and when to return to restart the tasks. The lunch schedule was monitored by alarms in certain projects. Other recommended strategies were to improve the transportation to the work site and proximal placement of cafeteria, portable toilets, and shelters. In addition, area planners were recommended to log and identify rain patterns so as to plan the work effectively and avoid the delay observed in this study. Another recommendation was to use the time during work stoppages due to bad weather for tool inspection, material/fabrication in workshop, skill assessments, and toolbox meetings. Material Transportation: Introducing innovative and intrinsically safe systems to transport material around the site locations and between floors could mitigate material handling time. For instance, a battery-operated scaffold puller may reduce workers involved in material handling and travel. Moreover, effective planning and management of project materials and equipment, was recommended.

\section{VALIDATION OF CONTINUOUS PRODUCTIVITY IMPROVEMENT}

Second round data collection was done in seven (of ten) projects with similar work scope to measure productivity improvement. As shown in Figure 1, the aggregate direct work increased from $31.7 \%$ to $35.6 \%$, while waiting, transport, travel, and personal time decreased between the two cycles. The 'Transport' category includes material handling and tools and equipment (MTE). Preparatory work time increased sharply. There was a redistribution of time in different work categories after implementing interventions. The direct work increased from $32.7 \%$ to $37.9 \%$ in construction projects and from $30.4 \%$ to $30.8 \%$ in maintenance projects. The slight improvement in maintenance projects was attributed to the long-established management pattern between operation and maintenance teams. Comparison of direct work by work hour in Figure 2 revealed that the first hour of a day-start and the hour after lunch benefited from the implemented solutions. 


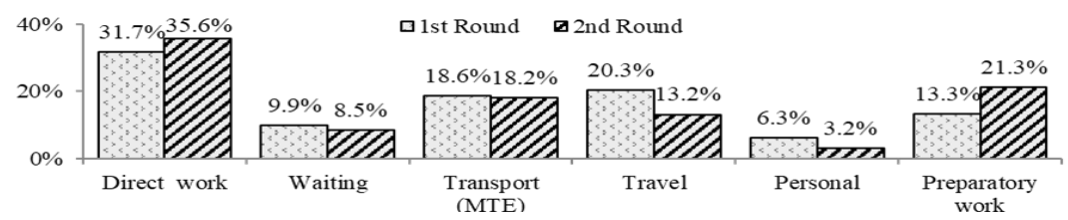

Figure 1: Comparison of aggregate worker time distribution between cycles

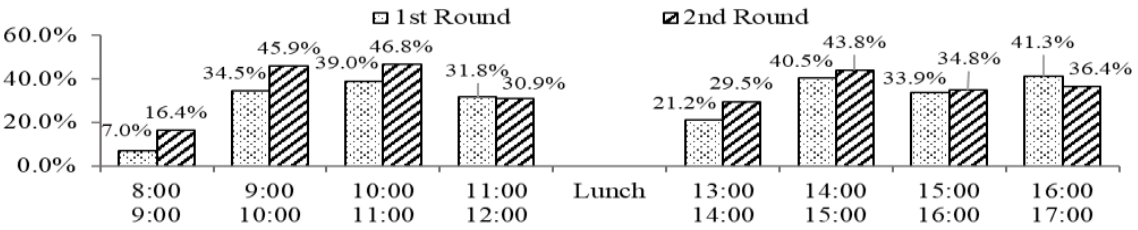

Figure 2: Comparison of direct work percentage by work hour between cycles

\section{CONCLUSIONS AND RECOMMENDATIONS}

This study developed and implemented a novel method for assessing productivity in maintenance activities, shutdowns, and turnarounds. The labour efficiency in various projects at petrochemical plants was assessed, the causes for non-value-added work hours were identified, and practices for improving productivity were recommended. Using a modified novel Activity Analysis method developed to reflect petrochemical plant conditions, two cycles of on-site assessments were conducted on pilot projects in Singapore's petrochemical plants. In the first cycle, comprising 10 projects, overall aggregate direct work percentage was $29.5 \%$. Workers were found to spend significant time on non-direct work namely travel $(23.8 \%)$, material handling $(15.7 \%)$, preparatory work (13\%) and waiting during the first hour of a workday. Hence this study recommended mitigation strategies such as advance issue of permits, utilisation of weather delays and implementation of efficient material transport systems. In the second cycle, the aggregate direct work percentage increased from $31.7 \%$ to $35.6 \%$, indicating an improvement after implementing the solutions. Notably, twelve projects in this study involved maintenance activities, shutdown, and /turnaround, which are seldom addressed in productivity studies, and hence an important contribution of this study. Although the objectives were achieved, there are some limitations. First, the limited number of projects since this was designed as a pilot study. Moreover, due to time and site constraints, only seven pilot projects were analysed in the second cycle. Therefore, the results of this study must be interpreted and generalized carefully. Nevertheless, the proposed method enables the petrochemical industry to assess and benchmark craft productivity during the construction and maintenance of these facilities. With further studies, a deeper understanding of the non-direct work categories and their specific correlation with productivity could be obtained.

\section{ACKNOWLEDGEMENTS}

This research was conducted by the Construction Industry Institute, University of Texas at Austin (UT), and National University of Singapore (NUS), as part of a research project 
Sriya Muralidharan, Pramesh Krishnankutty, Bon-Gang Hwang,

Carlos Caldas, Stephen Mulva

funded by the Singapore Economic Development Board (EDB) and companies from the Singapore process construction and maintenance sectors of the energy and chemical industries. The authors would like to thank all organisations and individuals that supported this study, especially those involved in the pilot projects.

\section{REFERENCES}

AACE International (2004). "22R-01: Direct labor productivity meansurement - as applied in construction and major maintenance projects."

Arbulu, R. J., and Tommelein, I. D. "Value stream analysis of construction supply chains: Case study on pipe supports used in power plants." Proc., IGLC-10, 183-195.

ASPRI (2015). <http://www.aspri.com.sg/productivity-initiative/>. (2017).

Auyong, H. (2014). "Singapore's Productivity Challenge: Part III." (2017).

Ballard, G., and Howell, G. (1994). "Implementing lean construction: stabilizing work flow." Lean construction, 101-110.

Ballard, G., and Howell, G. (1998). "Shielding production: essential step in production control." Journal of Construction Engineering and management, 124(1), 11-17.

Bernolak, I. (1997). "Effective measurement and successful elements of company productivity: The basis of competitiveness and world prosperity." International Journal of Production Economics, 52(1-2), 203-213.

Buchholz, B., Paquet, V., Punnett, L., Lee, D., and Moir, S. (1996). "PATH: a work sampling-based approach to ergonomic job analysis for construction and other nonrepetitive work." Applied ergonomics, 27(3), 177-187.

Caldas, C. H., Shounak, G. H. A., Hwang, B. G., Krishnankutty, P., Zhu, L., Mulva, S., and Oliveira, D. (2016). "Activity Analysis Pilot Projects - Singapore Petrochemical Industry." The University of Texas at Austin, National University of Singapore and Construction Industry Institute, Singapore, 121.

CII (2010). Guide to Activity Analysis, Construction Industry Institute, United States.

Dozzi, S. P., and AbouRizk, S. M. (1993). "Productivity in Construction "Canada.

EDB (2014). "Chemical Industry in Singapore."

ESC (2010). "Report of the Economic Strategies Committee."

Fish, E. (2015). "Interview: What an Aging and Shrinking Population Means for Japan."

Gong, J., Borcherding, J. D., and Caldas, C. H. (2011). "Effectiveness of craft time utilization in construction." Construction Management and Economics, 29(7), 737.

Gouett, M. C., Haas, C. T., Goodrum, P. M., and Caldas, C. H. (2011). "Activity analysis for direct-work rate improvement in construction." Journal of Construction Engineering and Management, 137(12), 1117-1124.

Hewage, K. N., and Ruwanpura, J. Y. (2006). "Carpentry workers issues and efficiencies related to construction productivity in commercial construction projects in Alberta." Canadian Journal of Civil Engineering, 33(8), 1075-1089.

Hwang, B. G., Tan, H. F., and Sathish, S. (2013f). "Capital project performance measurement and benchmarking in Singapore." Engineering, Construction and Architectural Management, 20(2), 143-159.

Ingvaldsen, T., Lakka, A., Nielsen, A., Bertelsen, N. H., and Jonsson, B. (2004). "Productivity studies in Nordic building-and construction industry."Norway. 
Josephson, P.-E., and Björkman, L. (2013). "Why do work sampling studies in construction? The case of plumbing work in Scandinavia." Engineering, Construction and Architectural Management, 20(6), 589-603.

Koskela, L. (1992). "Application of the New Production Philosophy to Construction."

Koskela, L. (2000). An exploration towards a production theory and its application to construction, VTT Technical Research Centre of Finland.

Liou, F. S., and Borcherding, J. D. (1986). "Work sampling can predict unit rate productivity." Journal of Construction Engineering and Management, 112(1), 90.

Ministry of Manpower (MOM) (2017). "Process sector: Work Permit Requirements."

MTI (2015). ""Economic Survey of Singapore 2015."." (2016).

Rakhra, A. "Construction productivity: concept, measurement and trends, organisation and management in construction." Proc., 4th Yugoslavian Symp. on Construction 487.

SPRING Singapore (2011). "A Guide to Productivity Measurement." SPRING Singapore.

Thompson, S. K. (1987). "Sample size for estimating multinomial proportions." American Statistician, 41(1), 42-46.

Tippett, L. (1935). "A snap reading method of making time studies of machines and operatives in factory surveys." Journal of British Textile Institute Transactions, 26.

Yi, W., and Chan, A. P. C. (2014). "Critical review of labor productivity research in construction journals." Journal of Management in Engineering, 30(2), 214-225. 